\title{
Optimization of the innovative design products' cost
}

\author{
Irina Yamshchikova ${ }^{1}$, and Yevgeny Naumov ${ }^{1, *}$ \\ ${ }^{1}$ Irkutsk National Research Technological University, 664074, Lermontova str., 83, Irkutsk, Russia
}

\begin{abstract}
The authors have suggested a block diagram on calculation of cost of design products, based on the utilization of analysis of the actual costs of design organization. The key blocks of the proposed calculation are the identification of duration of design procedures and analysis of the actual cost of the design organizations. The authors have performed analysis of the structure of the cost value of design products in the organizations representing the city of Irkutsk having divided them into the four following groups: large, medium, small and micro- organizations. Based on that, they have defined a share of labor costs in value of innovative design products. Data of accounting of design institutions of Irkutsk for 2015-2017 became a basis for the economic and statistical analysis. The calculated indicator of the share of labor costs in the cost value will constitute a reliable approach for identification of the cost of the design work when developing innovative design products.
\end{abstract}

\section{Introduction}

According to the data of experts of the Higher School of Economics, the sector of construction in Russia will overcome the crisis in 2018. In this connection the question of justification of the contract price for design of construction objects deserves more and more attention. Economic effectiveness of investments into construction objects, the character of its life cycle, continuity of functioning of the cost value of the produced products, and operating and working conditions in a substantial degree depend on the level of the design solutions.

The design projects have a big volume of survey, graphics and design material. In the process of design, some model research, numerous approvals, expertise and authorization of the completed technical documentation are carried out. All these demand not only enough time but money, the amount of which often impacts the final cost of the design.

The question of specification of the price of project production is offered by us for consideration in connection with the changed form of process of the design, which, as the computer technology and programming has been developing, has formed as the innovation process. Therefore, the methodological approach to the justification of the volume of investments, required for the development of innovation design products, needs some rethinking.

\footnotetext{
*Corresponding author: yamsirina@yandex.ru
} 


\section{Materials and methods}

Data of accounting of design institutions of Irkutsk for 2015-2017 have formed a basis for the economic and statistical analysis. The collection of data has been conducted with utilization of reporting and statistical methods.

Theoretical studies of the patterns have been implemented with utilization of mathematical statistics. According to the database "Kontragent" (the certificate of state registration of Rospatent №2009620480), that consists of the files of companies and documents connected with these files, we have compiled statistical tables, which became a basis for developing diagrams reflecting trends of changes in the structure of labor costs in the cost value of design products for the groups of organizations representing the city of Irkutsk.

\section{Results}

As a result of analysis of the methodology of calculation of the cost of design, we have identified the following methods of calculation that are currently being used [1,2]:

- Calculation of the cost of design in percentage of the cost of construction;

- Calculation of the cost of design cost depending on natural indicators;

- In case of the absence of price for design of a peculiar object, it can be calculated in accordance with the cost value and the existing level of profitability of organizations that develop the project documentation.

As the global experience indicates, the cost of design for many years has been defined in percentage of the cost of construction with differentiation on categories of the complexity of objects. In pre-revolutionary Russia, in the developed countries of Europe and America, as well as in the developing countries this methodology stood the test of time, and is still the dominant one in determining the value of designing of buildings and structures [3]. This methodology existed in Russia in the effective specialized chapters of the "Collection of prices for design work for construction", released 1987-1990. Later these Collections have been agreed with the level of prices on 01.01.1991.

An experience of utilization of this methodology has shown that the major difficulty of its adaptation to the contemporary conditions of design and construction in Russia was in difficulty of reliable determination of the cost of construction that is the basis for calculation the cost of design [4].

In 1995, for elimination of these shortcomings the Collections of basic prices for design for construction (CBP-95) were justified and published, and publications of 1995-1999 followed with prices agreed with the level of prices on 01.01.1995. Later, a new addition of these Collections was released for the level of prices on 2001 (CBP-01). The indicators of the cost of design in the Collections of basic prices are based on application of the natural indicators estimated for objects of mass construction (calculated per $1 \mathrm{sq}$. m. of total area, and 1 cubic meter of volume for industrial buildings). The major shortcoming of these Collections is a lack of adjustment of design cost taking into account application of innovative methods of calculation and registration of project documentation [5, 6].

In assessing the value of innovative design products, it is needed to take into account the changing duration of the design work that should be identified in accordance with the rules of technical regulation of the work of designers.

The regulation basis that is used today for the determination of the design costs (CBP-01) is based on outdated and unreasonable norms for the duration of the design products that does not properly take into account the innovation nature of the current design products [7]. The analysis of our results has shown that in connection with the development of information technologies in the sector of construction, appearance on the market of new, more universal, 
and more economically and technologically profitable construction materials, products and structures, development of the architectural image of housing, and introduction of new design software, utilization of regulatory documents in basic prices does not reflect reals costs for design of an object $[1,8,9,10,11]$.

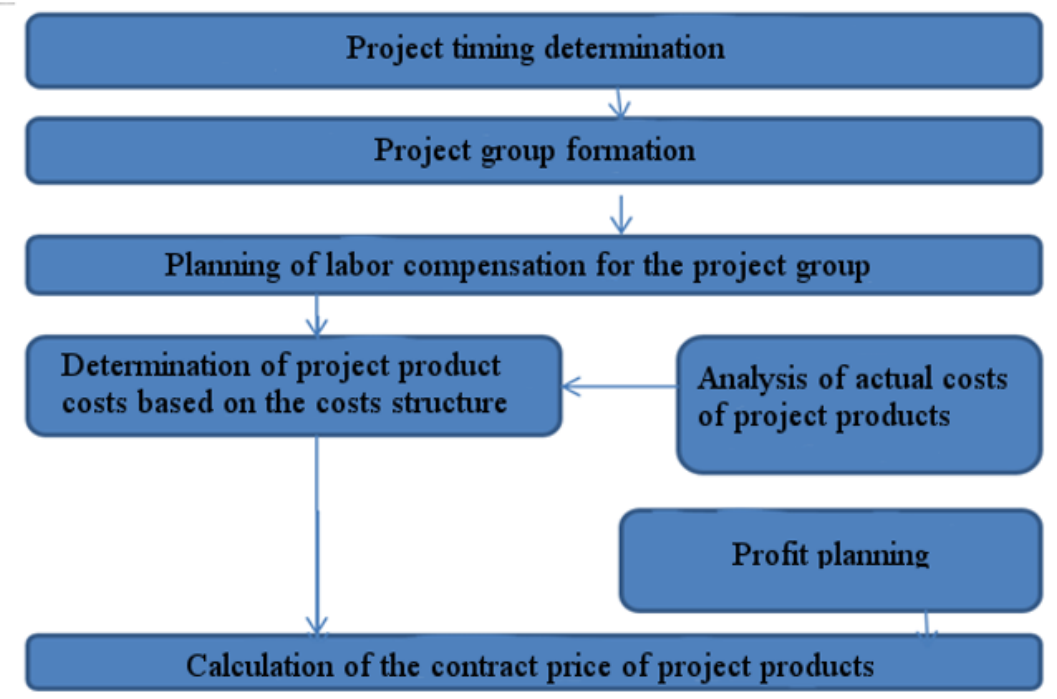

Fig. 1. Block diagram of the calculation of cost of the design products.

Based on the formulated above, we have proposed a method of identification of the cost of on the basis of the optimized indicators of duration of design [12]. We presented the suggested method in the following block diagram of the calculation (Figure 2).

In formation of the contract price for the design products, the analysis of actual cost, on which it is possible to define the structure of the cost value of products, is the most significant chapter. Justifying duration of design, it is possible to plan with the sufficient degree of preciseness funding for the payments, and then determine the cost rate using the cost structure in the most accurate way.

The authors have performed analysis of the actual cost value of products of design organizations of Irkutsk for 2015-2017. For this purpose, the design organizations representing the city have been grouped into the following categories: large organizations, medium, small and micro-organizations in accordance with the criterion of revenue.

Table 1. Structure of labor cost in the cost value of design products.

\begin{tabular}{|c|l|c|c|c|}
\hline \multirow{2}{*}{$№$} & \multicolumn{1}{|c|}{ Organizations } & \multicolumn{3}{|c|}{ Labor costs, \% } \\
\cline { 3 - 5 } & \multicolumn{1}{|c|}{ «Irkutsk institute } & 63.95 & 55.51 & 34.77 \\
\hline & Large companies & & & 2016 \\
\hline 1 & $\begin{array}{l}\text { OJSC } \\
\text { «Giprokommunvodokanal» }\end{array}$ & 52.44 & 50.34 & 36.62 \\
\hline 2 & OJSC «Irkutsk Promstroiproekt» & 56.03 & 65.33 & 62.84 \\
\hline 3 & OJSC «Irkutskgiprodornii» oil & 59.93 & 63.43 & 33 \\
\hline 4 & OJSC «Sibgiprobum» & $\begin{array}{l}\text { OJSC «Angarsk Institute for design of } \\
\text { refining and petrochemical enterprises» }\end{array}$ & 39.34 & 34.76 \\
\hline 6 & $\begin{array}{l}\text { OJSC «Siberian scientific-research, development } \\
\text { and design Institute for aluminium and electrode } \\
\text { industry» }\end{array}$ & 49.2 & 39.54 & 46.1 \\
\hline
\end{tabular}




\begin{tabular}{|c|c|c|c|c|}
\hline 7 & OJSC «Siberian Orgstroiproekt» & 51.95 & 47.39 & 41.94 \\
\hline 8 & $\begin{array}{l}\text { LLC «Ust-Ilimsk design and engineering } \\
\text { technological bureau» }\end{array}$ & 60.66 & 61.8 & 54.14 \\
\hline & Medium enterprises & & & \\
\hline 1 & OJSC "Irkutskgrazhdanproekt" & 42.68 & 32.59 & 40.27 \\
\hline \multirow[t]{2}{*}{2} & CJSC "Elektrosetproekt" & 54.44 & 77.2 & 70.95 \\
\hline & Small enterprises & & & \\
\hline 1 & CJSC "VostSibProekt" & 43.81 & 54.41 & 69.69 \\
\hline 2 & $\begin{array}{l}\text { OJSC Design research institute } \\
\text { "Irkutskgiprolestrans" }\end{array}$ & 30.03 & 24.02 & 11.41 \\
\hline 3 & CJSC "Eastern Geophysics Trast" & 58.04 & 63.06 & 58.12 \\
\hline 4 & CJSC "Engineering center PROFIS" & 59.62 & 61.64 & 44.69 \\
\hline 5 & LLC "Vostokgiproshakht" & 54.08 & 43.96 & 47.52 \\
\hline 6 & OJSC "Design technological institute" & 73.91 & 69.42 & 67.59 \\
\hline 7 & OJSC "Design technological institute" & 72.8 & 75.03 & 71.88 \\
\hline 8 & LLC NPP Enprof & 53 & 54,6 & 60 \\
\hline 9 & LLC "Primier-Energo" & 63.11 & 65.13 & 58.47 \\
\hline 10 & LLC "Sarma-B" & 48.45 & 46.34 & 33.33 \\
\hline 11 & LLC "Sota=Angarsk" & 49.29 & 52.13 & 43.54 \\
\hline 12 & LLC "Firma Transproekt" & 54.38 & 59.56 & 49.03 \\
\hline 13 & LLC "Spetsproekt" & 42.66 & 54.38 & 57.14 \\
\hline 14 & $\begin{array}{l}\text { Production cooperative design organization } \\
\text { "Irkutskagrostroiproekt" }\end{array}$ & 59.31 & 63.48 & 44.89 \\
\hline \multirow[t]{2}{*}{15} & LLC "Firma Kompromiss" & 34.35 & 49.85 & 41.01 \\
\hline & Micro-companies & & & \\
\hline 1 & $\begin{array}{l}\text { LLC «Angarsk research and production } \\
\text { association «Energy» }\end{array}$ & 56.78 & 65.03 & 60.1 \\
\hline 2 & LLC "ZD-project" & 56.31 & 60.28 & 43.01 \\
\hline 3 & LLC «Engineer Davydov» & 54.11 & 58.21 & 55.05 \\
\hline 4 & LLC "Micron" & 59.42 & 55.11 & 54.69 \\
\hline 5 & LLC Firm "Absolute" & 47.49 & 50.31 & 53.48 \\
\hline 6 & LLC «Environment and enterprises project» & 56.35 & 44.31 & 56.39 \\
\hline 7 & $\begin{array}{l}\text { LLC Personal creative architectural workshop } \\
\text { "Studio-7" }\end{array}$ & 48.57 & 61.39 & 55.32 \\
\hline 8 & LLC "Ekotekhnolog" & 55.03 & 59.28 & 68.32 \\
\hline 9 & LLC "PromTekhEko" & 69.34 & 54.32 & 57.43 \\
\hline
\end{tabular}

Based on the Table, we see that the average rate of the structure of labor cost in the cost value of large enterprises decreases from $56.9 \%$ in 2015 , to $43 \%$ in 2018 , and it is equal to $50.86 \%$ for the analyzed years in average. Graphically it looks like this:

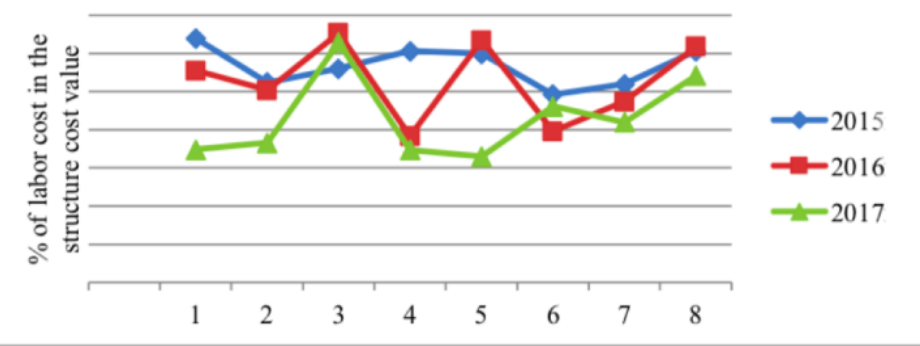

Fig. 2. The structure of labor cost in the cost value of the design products in large companies. 
For medium design companies, the average rate of the structure of labor cost is increasing from $48.6 \%$ to $55.6 \%$. Small and micro-companies demonstrated in 2016 the increase of the structure of wage with subsequent decrease.

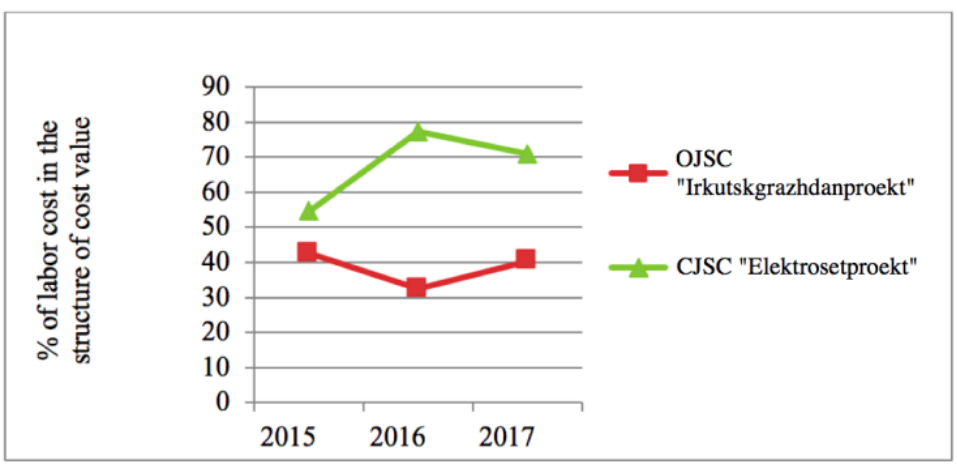

Fig. 3 The structure of labor cost in the cost value of the design products in medium companies.

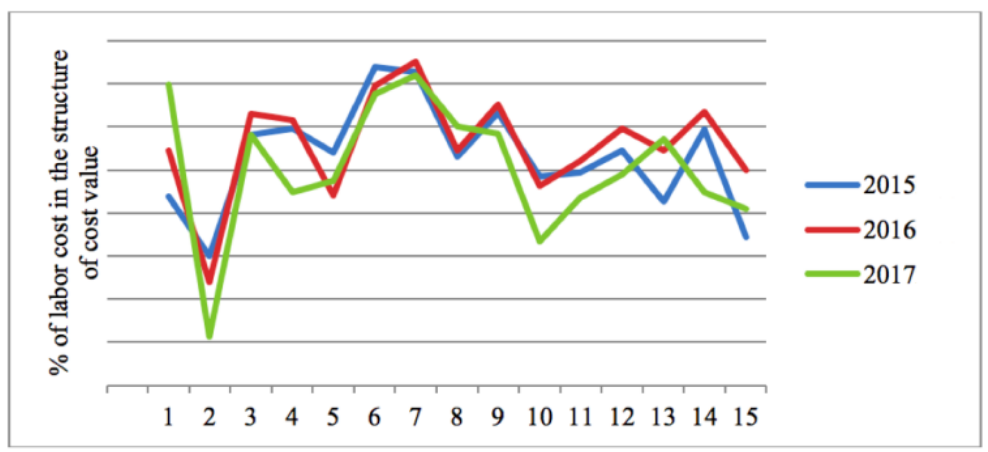

Fig. 4. The structure of labor cost in the cost value of the design products in small companies.

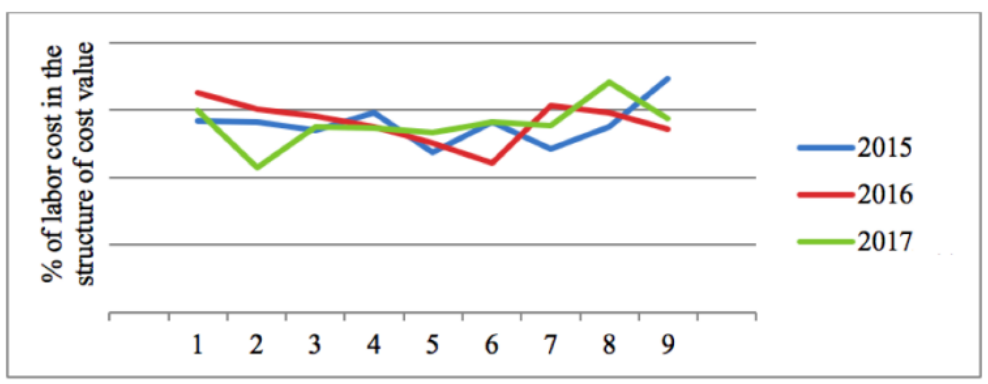

Fig. 5. The structure of labor cost in the cost value of the design products in micro-organizations

\section{Discussion}

The generalization of foreign experience in the issue of determination of design costs indicates the presence of both negative and positive moments. This question has always been granted with a lot of attention abroad (in the USA, Germany, Switzerland, Japan, Poland, Turkey, the Great Britain, and France), and the collected data testify that $[13,14,15,16,17]$. So, for example, in Germany in the beginning of 1980s new regulations for the determination of design cost based on the present ratio of expenses for construction and assembling works 
and the used volume of capital investments were elaborated. The uniform prices for certain types of design work and design costs for certain types of construction were represented in the Collections. Also, the analysis of innovative methods of design was implemented, as a result of which the level of prices in the new system became higher by $16 \%$. Similar research took place in America. The company "Hector Holguin and Associates" payed attention that the average cost of development of working drawings for a typical constructive node manually was about $\$ 12.5$, and with the use of computers just $\$ 2.5$. Thus, there was a decrease of price by $80 \%$ as a result of the use of innovative methods of development of working drawings. In the meantime, the Construction Industry Computing Association offers for use a package of 700 construction design programs. It would inevitably lead to the additional costs for the design organizations and increase the cost value of the innovation design products.

There are no publications on results of bibliographic review of similar national economic comparisons. The questions of identification of design costs based on the labor cost have been presented in the works of some Moscow researchers [7]. However, in the method suggested by them we do not find a source of determination of the planned duration of implementation of design works and a number of designers.

For introduction of the block diagram of calculation of cost of the design products the authors have offered, it is needed to carry out the procedure of standardization of labor input of design works taking into account innovation changes in the design procedure. New standards of duration of design or implementation of innovative design products can become the results of such calculations.

\section{Conclusion}

Based on the formulated above, the authors have suggested a block diagram on calculation of the cost of design based on the structure of costs of design organizations. It is needed to carryout additional research of some parameters in order to calculate the optimal rate of the design cost, the first of which is duration of design. This indicator must be optimized taking into account innovative decisions for every types of the design products. For introduction of the proposed methods of calculation, the authors have analyzed the structure of cost value of the design organizations in the city of Irkutsk for 2015-2017, Table 2.

Table 2. The average structure of labor cost in the cost value.

\begin{tabular}{|c|c|c|c|c|}
\hline \multirow{2}{*}{ Organizations } & \multicolumn{3}{|c|}{ Labor cost, \% } & \multirow{2}{*}{$\begin{array}{c}\text { Average index, } \\
\%\end{array}$} \\
\cline { 2 - 4 } & 2015 & 2016 & 2017 & 50.86 \\
\hline Large companies & 56.9 & 52.7 & 43.0 & 53.0 \\
\hline Medium companies & 48.6 & 54.9 & 55.6 & 53.16 \\
\hline Small companies & 53.1 & 55.8 & 50.6 & 56.13 \\
\hline Micro-companies & 55.9 & 56.5 & 56.0 & \\
\hline
\end{tabular}

In average, in the design organizations representing the city of Irkutsk, the structure of labor cost in the cost value is at the level of $53.3 \%$.

\section{References}

1. I. V. Yamshchikova, Herald of INJECON. Series in Economy, 7, 61-67 (2011) 
2. E. S. Dedyukhina, Izvestiya Vuzov. Investments. Building. Real Estate, 4(15), 26-32 (2015)

3. O. N. Borovskikh, Russian Entrepreneurship, 18(22), 3393-3404 (2017)

4. D. A. Malshakova, Young Scientist, 49(183), 185-189 (2017)

5. T. V. Mashoshina, Bulletin of the Results of Scientific Research, 4 (9), 102-114 (2013)

6. M. S. Korableva, Proceedings of the Krylov State Research Center, 70(354), 35-43, (2012)

7. E. A. Igoshin, Vestnik MGSU, 12(1), 46-52 (2017)

8. G. M. Okhezina, Creative Economy, 12, 56-61 (2011)

9. V. V. Buzirev, E. I. Naumov, Izvestiya Vuzov. Investments. Building. Real Estate, 1(4), 55-58 (2013)

10. A. V. Lyapin, V. Yu. Lyapin, Scientific Review, 8, 251-255, (2016)

11. T. V. Dobysheva, Izvestiya Vuzov. Investments. Building. Real Estate, 1(12), 33-38 (2015).

12. I. V. Yamshchikova, E. I. Naumov, Proceedings of the Irkutsk State Technical University, 3(50), 26-41 (2011).

13. M. Y. Veselovsky, M. A. Izmailova, A. V. Bogoviz, S. V. Lobova, Y. V. Ragulina, Quality - Access to Success, 19(163), 30-36 (2018)

14. L. Fernandez, J. J. Dolado, Information and Software Technology, 41(7), 421-434 (1999)

15. K. Hodicky, T. Hulin, J. W. Schmidt, H. Stang, S. Hansen, Structural and Multidisciplinary Optimization, 52(6), 1089-1106 (2015)

16. A. V. Bogoviz, S. V. Lobova, A. N. Alekseev, I. A. Koryagina, T. V. Aleksashina, Advances in Intelligent Systems and Computing, 622, 609-616 (2018)

17. E. Mostavi, S. Asadi, D. Boussaa, Energy, 121, 606-615 (2017) 